\title{
The Harshness Objection: Is luck egalitarianism too harsh on the victims of option luck?
}

\author{
Kristin Voigt \\ Final version published in Ethical Theory and Moral Practice 2007, 10(4), 389-407.
}

\begin{abstract}
According to luck egalitarianism, inequalities are justified if and only if they arise from choices for which it is reasonable to hold agents responsible. This position has been criticised for its purported harshness in responding to the plight of individuals who, through their own choices, end up destitute. This paper aims to assess the Harshness Objection. I put forward a version of the objection that has been qualified to take into account some of the more subtle elements of the luck egalitarian approach. Revising the objection in this way suggests that the Harshness Objection has been overstated by its proponents: because luck egalitarians are sensitive to the influence of unequal brute luck on individuals' choices, it is unlikely that there will be any real world cases in which the luck egalitarian would not have to provide at least partial compensation. However, the Harshness Objection still poses problems for the luck egalitarian. First, it is not clear that partial compensation will be sufficient to avoid catastrophic outcomes. Second, the Harshness Objection raises a theoretical problem in that a consistent luck egalitarian will have to regard it as unjust if any assistance is provided to the victim of pure option luck, even if such assistance could be provided at no cost. I consider three strategies the luck egalitarian could pursue to accommodate these concerns and conclude that none of these strategies can be maintained without either violating basic luck egalitarian principles or infringing upon individual liberty.
\end{abstract}

KEYWORDS. choice; equality; harshness; luck egalitarianism; option luck.

\section{Introduction}

Recent theories of equality emphasise the importance of individual responsibility in determining just distributive outcomes: distributions should, as a matter of justice, reflect the choices that it is reasonable to hold agents responsible for, while the effects of "brute luck" must be compensated for. This approach to social justice, which has been termed "luck egalitarianism" (Anderson, 1999a, p. 289), has been associated with theorists such as Richard Arneson (1989, 1990), G. A. Cohen (1989, 2004) and Ronald Dworkin (1981, 2000, 2002, 2003). ${ }^{1}$

The focus of this paper is what I will call the Harshness Objection, a criticism frequently raised against luck egalitarianism. This objection focuses on luck egalitarians' perceived harshness in responding to cases where individuals, as a matter of "option luck" (i.e. through risks they voluntarily accepted), ${ }^{2}$ end up in abject circumstances. Because the luck egalitarian is committed to letting people bear the costs of their choices, no matter how high these costs may

1 Each of these theorists favours a different interpretation of the basic luck egalitarian idea. Note also that Dworkin has in fact rejected the label "luck egalitarian" for his theory (Dworkin, 2003, pp. 190-191). In the argument presented in this paper, I follow Cohen and Arneson in linking brute luck to the absence of agent control. I reject Dworkin's view that certain conditions in which people find themselves cannot be regarded as a matter of brute luck, irrespective of their inability to control these conditions, but cannot provide an argument to this effect here.

2 See Dworkin (1981 [2000, p. 73]) for the distinction between "option luck" and "brute luck". 
be, she can provide no assistance to the victims of bad option luck without violating her principles of equality. Two proponents of the Harshness Objection are Marc Fleurbaey (1995) and Elizabeth Anderson (1999a, 1999b). The objection is illustrated by examples such as the case of Bert, who likes to ride his motorbike without wearing a helmet. During one of his rides, he has an accident which leaves him with severe head injuries that will prove fatal unless he receives surgery. Even if this operation could be performed at little or even no cost, the luck egalitarian would have to deny Bert treatment because his suffering is a result of his choice: "the faulty driver has no claim of justice to... medical care" (Anderson, 1999a, p. 296).

A number of recent papers have pointed to some important problems with the Harshness Objection as it stands: Alexander Kaufman (2004) and Carl Knight (2005) challenge Anderson's reading of luck egalitarianism. They suggest that luck egalitarians provide a more subtle approach which does not commit them to the degree of harshness suggested by Anderson. Nicholas Barry (2006) emphasises that many choices are made under conditions (such as incomplete knowledge and unequal opportunities) that make it unreasonable to hold agents fully responsible for those choices; for the luck egalitarian, the fact that an inequality is created by an agent's choice is not sufficient reason to deny compensation. The aim of this paper is to provide a more detailed and more systematic assessment of the Harshness Objection, and to determine the extent to which the luck egalitarian project is undermined by a version of the Harshness Objection that takes account of the subtleties of the luck egalitarian approach. I suggest that the force of the Harshness Objection has been overstated by its proponents. On a reasonable interpretation of the brute luck-option luck distinction, luck egalitarians will always provide at least some compensation to agents who, through their choices, end up in desperate situations. Because the choices people make are to at least some extent affected by unequal brute luck, the luck egalitarian will not hold individuals fully responsible for the costs of such choices. However, this does not fully rebut the Harshness Objection. First, it may be that the partial compensation warranted by the influence of unequal brute luck is insufficient to avoid the catastrophic outcome faced by the agent. Second, whatever the practical relevance of the Harshness Objection, it still poses a theoretical problem for luck egalitarians: they are endorsing a theory according to which it is unjust to provide assistance to the victims of pure option luck, even if this assistance could be provided at no cost. I consider three possible responses to these problems before concluding that all of these strategies are problematic: they require either that we violate basic luck egalitarian principles or that we impose restrictions on individual liberty.

Two preliminary remarks should be made at this point. First, the Harshness Objection claims that luck egalitarianism can provide no assistance to the option luck victims as a matter of equality. This is different from the question of whether the luck egalitarian must deny assistance to the option luck victim, all things considered. As Larry Temkin (2003, p. 63) notes, "any reasonable egalitarian will be a pluralist. Equality is not the only thing that matters to the egalitarian." ${ }^{3}$ On the pluralist account, the luck egalitarian could cite non-egalitarian reasons such as compassion, benevolence or charity to aid the option luck victim; however, she would have to concede that in baling out the option luck victim, she is acting contrary to the requirements of her

3 Two different kinds of pluralism can be distinguished in this context, depending on how the relationship between equality and justice is conceived. Some theorists, such as Cohen $(1989,2004)$ and Kymlicka (2006), identify equality and justice, the requirements of which have to be weighed against other commitments. Others suggest that equality is one of the values that must be weighed against other considerations to determine the requirements of justice (e.g. Vallentyne, 2002; Otsuka, 2004a). The first view is criticised by Miller (1997). 
theory of equality. This paper focuses on how the luck egalitarian must respond to the situation of the option luck victim qua luck egalitarian; this response might be different from what the (pluralist) luck egalitarian might regard as the "right" response, all things considered.

Second, it is important to note that the luck egalitarian account, as I understand it, identifies an equal distribution as one that is affected only by equal brute luck and option luck, and any departures from this distribution are understood as increasing inequality. This includes departures from an equal distribution that are created by voluntary transfers from one individual to another, to the extent that these are a matter of unequal brute luck for the recipient. ${ }^{4}$ In the context of the Harshness Objection, this means that if luck egalitarianism requires that the option luck victim not be given assistance, then not only is no one required, as a matter of justice, to help the option luck victim; luck egalitarians would have to oppose such transfers, even if they are voluntary. ${ }^{5}$

I begin this paper by considering possible reasons for the appeal of the Harshness Objection (section 2). Section 3 considers the conditions under which the Harshness Objection can apply. I suggest that the objection can have full force only with respect to outcomes that are a result of pure option luck. Furthermore, where any aid provided for the option luck victim is associated with opportunity costs, the case for the Harshness Objection is weakened. I end section 3 by stating the Harshness Objection in what I take to be its strongest form. Section 4 considers three strategies the luck egalitarian could pursue to address the problems raised by the objection. I conclude that these strategies remain problematic because they would either require that we compromise the unified, singular standard that underlies luck egalitarianism as it stands, or involve restrictions on individual liberty.

\section{$2 \quad$ The appeal of the Harshness Objection}

Before we assess the Harshness Objection as a challenge to luck egalitarianism, it will be useful to consider what exactly it is about this objection that raises concerns about luck egalitarianism as an appropriate understanding of equality. Four possible suggestions are addressed in this section. First, proponents of the Harshness Objection often suggest that the luck egalitarian's purported reaction to the victims of option luck is a way of apportioning undeserved punishment. The vocabulary of retributive justice, however, is inappropriate and imputes objectives to the luck egalitarian that she does not share. A further implication that might be read into the Harshness Objection - that luck egalitarians pay no attention to the relationship between the likelihood of a risk and the severity of the outcome associated with it - must be qualified. It is true, however, that luck egalitarians cannot take into account the relative importance of what is being put at risk by certain choices; it cannot accommodate the idea that the satisfaction of basic needs, for example, requires special consideration within a theory of justice. Most importantly, however, luck egalitarianism does not seem to accommodate any duty we might feel to relieve extreme suffering, irrespective of the agent's role in bringing about her suffering.

\subsection{Limits to deserved punishment}

4 This underlines the luck egalitarian case for taxing inheritance although Rakowski (1991) suggests that option luck can play a role in determining what bequests individuals receive.

5 It is important to remember that this point holds only in the context of a fully equal distribution. In the real world, where distributions are highly unequal, charitable giving is likely to enhance equality and would be welcomed by luck egalitarians; bequests, to the extent that they increase rather than redress inequality, would remain questionable. 
Advocates of the Harshness Objection often imply that what is involved in deciding that an agent's suffering should not be relieved amounts to meting out punishment. For example, Fleurbaey states that "the scale of penalties must not be so harsh" (Fleurbaey, 1995, p. 41), and he notes that "[o]ur society cures its criminals when they are injured, because this kind of physical penalty is not considered appropriate. In the light of [the Bert] example, the equal opportunity principle [i.e. the luck egalitarian approach] looks rather primitive." (Fleurbaey, 1995, p. 41) Similarly, Anderson argues that the victims of option luck "don't deserve the equivalent of the death penalty, even for... irresponsible behavior" (Anderson, 1999b).

In response to this, it is important to note that any characterisation of the luck egalitarian position as "punishing" those it denies assistance (and, presumably, "rewarding" those it compensates) is misleading. Commonly, we think about punishment and reward as expressing moral blame and praise. Luck egalitarians, however, are not involved in moral evaluations when deciding whether or not a given inequality is just. Luck egalitarianism is not trying to establish a "moral meritocracy" (Arneson, 1999b), where resources are distributed so as to reflect people's differential deservingness as measured by the virtue or vice of their characters or actions. Rather, the aim of luck egalitarian intervention is to rectify a situation of inequality; the redistributive actions such intervention might involve do not reflect moral appraisals of the agent or her actions.

\subsection{The disproportionate results of risk-taking}

The Harshness Objection can also be read as pointing out the luck egalitarian's failure to take account of the relationship between the probability that a certain outcome will occur and the severity of that outcome. Robert Goodin $(1985)^{6}$ argues that disastrous outcomes are not deserved, even when agents willingly and knowingly take the risks leading to those outcomes. He attempts an answer to the question of what it is that these agents do in fact deserve by arguing that when we make a risky choice that involves a disastrous outcome with a probability of $\mathrm{n} \%$, then what we deserve is $1 / n$-th of the suffering associated with that outcome:

Consider... someone who takes risks with his or her health - driving without fastening the seat belt, for example. He or she has done something silly, and in some sense deserves to suffer the consequences of such silliness. But being thrown through the windshield is surely far more punishment than he or she could be said to deserve. He or she was, after all, running only a 1 in 10,000 chance of crashing. His or her deserts... would be only $1 / 10,000$ th of the pain he or she suffers going through the windshield. (Goodin, 1985, p. 585, footnotes omitted)

This entails, Goodin explains, that where people's risky choices leave them in disastrous situations, we should try to alleviate their suffering, but "[m]aybe not all their suffering. After all, they deserve some pain... But more often than not nature takes care of that for us. People will typically have suffered some losses that we can do nothing to set right..." (Goodin, 1985, p. 585, footnote omitted). This argument implies that the outcome of a certain choice should be in some way proportionate to the probability of that outcome: if I choose a gamble that involves a $5 \%$ chance of being killed, I "deserve" a worse outcome than if I had chosen a gamble that involved a $0.5 \%$ chance of the same outcome.

6 While Goodin is not responding to luck egalitarianism and despite the differences between luck egalitarian and desert-based approaches, his argument captures an idea that could support the Harshness Objection. 
It is true that luck egalitarianism does not directly cater for this idea: from a luck egalitarian perspective, if someone, as a matter of pure option luck, decides to take a certain risk, then no attention must be paid to the relationship between the relevant probabilities and the severity of the outcome suffered by the agent. However, as will be explained in the next section, the luck egalitarian will take into account probabilities associated with certain risks in deciding whether or not the decision at hand really is a matter of pure option luck. People face a variety of risks in everyday life, many of which are associated with very small probabilities, which it would be unreasonable to expect agents to avoid; failing to avoid such risks does not automatically convert them into matters of pure option luck.

\subsection{The special status of basic needs}

A further intuition supports the Harshness Objection: we can distinguish between different goods and needs, and their importance for human well-being or ability to operate within a certain context. According to some theorists, a theory of justice should give special consideration to goods and needs that are different in this way. Anderson, for example, suggests that an appropriate theory of justice

must identify certain goods to which all citizens must have effective access over the course of their whole lives. Some goods are more important from an egalitarian point of view than others, within whatever space of equality is identified as of particular concern for egalitarians. And starting-gate theories, or any other principles that allow law-abiding citizens to lose access to adequate levels of these goods, are unacceptable (Anderson, 1999a, p. 314, emphasis added).

In Anderson's own approach of what she calls democratic equality, the goods and needs that are identified in this way are those necessary to ensure the individuals' potential for democratic citizenship, but we can think of different criteria according to which we could single out certain needs or goods for special considerations. Central to this approach is the idea that citizens should not be allowed to forego access to these goods.

From this perspective, luck egalitarianism can be criticised for failing to treat questions of, for example, how the gains of a lottery win should be shared differently from cases where people are at fatal risk. The luck egalitarian must concede that her approach does not give her a reason to or even allow her to - distinguish between certain goods or needs and to treat differently those singled out as particularly important or basic.

\subsection{The duty to relieve suffering}

Probably the strongest intuition underlining the importance of the Harshness Objection is the desire, or perhaps even duty, we feel to relieve (especially extreme) suffering. Jamie Mayerfeld, for example, states that

[w]e have a prima facie duty to relieve suffering, because suffering is bad and ought not to occur. Suffering is bad... not only for the individual whom it afflicts, but bad from an impersonal point of view. Its occurrence makes the world that much worse. (Mayerfeld, 1999, p. 111) 
Attempting to justify the existence of suffering - as, so the proponents of the Harshness Objection, luck egalitarians do - seems to contradict some of our strongest intuitions. Especially when there is no or very little cost to relieving the suffering of the option luck victim, could it really be unjust to do so?

\section{$3 \quad$ Qualifying the Objection: Pure option luck and the (individuated) standard of reasonable expectations}

In assessing the Harshness Objection, we first need to determine what exactly the Objection consists in and under which conditions it applies. The Harshness Objection is raised in connection with outcomes that are very severe and negative for the agent involved. Typically, proponents of the Objection use examples about agents who will be unable to meet even their most basic needs unless intervention takes place. If such situations arise out of agents' voluntary choices, the critics argue, the consistent luck egalitarian must deny assistance. Because the agents chose the risky option that led to their predicament, the luck egalitarian cannot intervene without violating her theory of equality. However, the objection has full force only when the outcome in questions is a matter of pure option luck; where the outcome has been affected by unequal brute luck, there is a case for luck egalitarian intervention. This section explores what it means for an outcome to be a matter of pure option luck and what this implies for the luck egalitarian's assessment of inequalities arising from individuals' choices.

\subsection{Pure option luck I}

The Harshness Objection has full force only where the relevant outcome results from pure option luck: only where a choice is purely a matter of option luck will luck egalitarianism require that no assistance be given. To the extent that unequal brute luck is involved in bringing about a catastrophic outcome, luck egalitarians have a reason to intervene. Furthermore, luck egalitarians have a more subtle understanding of the brute luck-option luck distinction than proponents of the Harshness Objection imply. From the luck egalitarian perspective, that an agent has made a "voluntary choice" is certainly not sufficient reason to hold her fully responsible for the outcome; we must also take into account the effects of unequal brute luck on this choice. Consider, for example, situations where an agent's range of choices was diminished by unequal brute luck so as to leave her no other choice than one involving the possibility of a life- or health-threatening outcome: where agents are forced, through no fault of their own, to take certain risks, their suffering a bad outcome as a result of this is not (purely) a matter of option luck, and the luck egalitarian will provide (at least partial) compensation. ${ }^{7}$

This point and its far-reaching consequences are not always recognised in the literature. Even some luck egalitarians have assumed that luck egalitarianism requires us to hold people responsible for the outcomes of virtually any of their choices, paying little attention to the extent to which these choices may have been affected by unequal brute luck. Eric Rakowski, for example, suggests that

[i]f a citizen of a large and geographically diverse nation like the United States builds his

7 I am not addressing the question of how the exact amount of compensation is to be determined. Rather, I argue that in many of the examples proponents of the Harshness Objection use to support their critique, there is good reason to think that there is a case for luck egalitarian intervention (even if this does not amount to full compensation). 
home in a floodplain, or near the San Andreas fault, or in the heart of tornado country, then the risk of flood, earthquake, or crushing winds is one he chooses to bear, since those risks could be all but eliminated by living elsewhere. (Rakowski, 1991, p. 79)

He concedes that the situation might be different if people are effectively physically unable to move but in general, he says, we can assume that "[o]ption luck... predominates in the case of property loss from natural disaster" (Rakowski, 1991, p. 79). Clearly, this is not the response the luck egalitarian has to give: it is consistent with luck egalitarianism to consider the process through which someone came to face a certain set of possible choices. If it is through unequal brute luck that the range of choices open to someone does not contain any satisfactory options, then a luck egalitarian will certainly not hold that person (fully) responsible for picking whatever option seems least disadvantageous. In fact, Arneson suggests that we think about his interpretation of luck egalitarianism - equal opportunity for welfare - in terms of equivalent decision trees open to people:

For equal opportunity for welfare to obtain among a number of persons, each must face an array of options that is equivalent to every other person's in terms of the prospects for preference satisfaction it offers. ... Equal opportunity of welfare obtains among persons when all of them face equivalent decision trees - the expected value of each person's best ( = most prudent) choice of options, second-best ... nth-best is the same. (Arneson, 1989, pp. 85-86, footnote omitted)

Where this condition is not met, the luck egalitarian will have reason to intervene; choices made under unequal conditions are not the kind of choices luck egalitarians want to hold individuals fully responsible for.

So what are the features of choices that luck egalitarians are willing to hold people fully responsible for? I noted earlier that according to luck egalitarianism, people can be held fully responsible for their choices only if these choices are a matter of pure option luck. To see when this condition would be met, it will be necessary to say more about the distinction between brute luck and option luck. First, note that it is not brute luck per se that the luck egalitarian is worried about; it is inequalities arising from unequal brute luck that require compensation. If two agents were to strand on a desert island, the amount of resources they would find there would be a matter of brute luck. However, as long as these resources are distributed equally between the two agents, it does not matter how high each person's share of resources is; the distribution is equal. Second, on the approach I suggest here, for a choice to be a matter of pure option luck, agents must be choosing against a background of equality, i.e. the background must be determined only by equal brute luck and pure option luck. Where unequal brute luck affects the choice - for example by diminishing the set of options available to one of the agents - we cannot say that the decision is a matter of pure option luck; the luck egalitarian will therefore treat any inequalities resulting from these choices as potential cases for (partial) compensation.

We can see why this point is important when we think about insurance decisions, which feature frequently when the Harshness Objection is raised. We cannot consider a person's insurance decisions a matter of pure option luck (and hence hold her fully responsible for not having insured) as long as factors of brute luck are affecting these decisions. Imagine, for example, a person who, through unequal brute luck, is too poor to afford a certain insurance policy. Because it is unequal brute luck that narrows the range of options available to her, it would be inconsistent 
with the luck egalitarian approach to regard her "choice" not to insure as a matter of option luck and to deny assistance if she faces disastrous outcomes as a result of being uninsured.

This point addresses what Anderson calls the problem of the "abandonment of the prudent" (Anderson, 1999a, p. 298, emphasis omitted). She notes that for people on very low incomes it may be unreasonable to take out insurance if insurance payments will make it impossible for them to provide for the basic needs of their families. However, to the extent that someone's low income is a result of brute luck, the luck egalitarian will not regard such insurance decisions as a matter of option luck (contra Anderson, 1999a, p. 298).

\subsection{Pure option luck II: The (individuated) standard of reasonable expectations}

Luck egalitarians sometimes phrase the brute luck-option luck distinction in terms of the more familiar distinction between "chance" and "choice". This, however, is somewhat misleading in that the fact that someone made a certain choice is not sufficient to transform the outcome of that choice into a matter of option luck. Consider Dworkin's description of the distinction between option luck and brute luck:

Option luck is a matter of how deliberate and calculated gambles turn out - whether someone gains or loses through accepting an isolated risk he or she should have anticipated and might have declined. Brute luck is a matter of how risks fall out that are not in that sense deliberate gambles. ... If I am hit by a falling meteorite whose course could not have been predicted, then my bad luck is brute (even though I could have moved just before it struck if I had had any reason to know where it would strike). (Dworkin 1981 [2000, p. 73])

The last sentence is particularly important here: Dworkin suggests that even where an agent could have made choices to avoid a certain risk, this is not necessarily enough to make that risk a matter of option luck. To draw the distinction between option luck and brute luck we must make certain normative judgements about what we can reasonably expect from agents (Stemplowska, 2002; Vallentyne, 2002). For example, I could avoid the risk of being hit by a car by never leaving my house. However, it seems unreasonable to expect people to do this, and the luck egalitarian is not going to deny compensation to someone who was hit by a car on the grounds that they made a "choice" to leave the house; this choice is not enough to make the outcome in question a matter of option luck. The availability of insurance will of course affect what we think we can reasonably expect agents to do. It might not be reasonable to expect someone to know where the meteorite would hit, but if insurance against this type of brute luck is available and affordable, we might think it reasonable that such insurance is bought. The standard of reasonable expectations, then, is necessary to determine whether someone's being exposed to a certain risk is a matter of option luck or of brute luck.

Furthermore, the standard of reasonable expectations we apply will have to be appropriately individuated $^{8}$ to take account of the agent's particular circumstances that might diminish her responsibility. For instance, if we were told that Bert had just found out that his mother had died, and he forgot to put on his helmet when he went off on his motorbike, we are likely to hold him less responsible than we might otherwise do. We would expect that factors of luck play a signifi-

8 I take the term "individuate" from Robinson and Darley (1995), pp. 116-123. Robinson and Darley's study tests people's intuitions about deserved punishment in criminal law cases. The US legal code around the "reasonable person" standard used in negligence cases allows the jury to individuate this standard if the defendant's circumstances seem to warrant it. 
cant role in determining what we can reasonably expect of individual agents, and what standard of reasonableness will be appropriate for the agent given her particular circumstances.

To see how this standard weakens the force of the Harshness Objection, consider two arguments proponents of this objection put forward: first, that luck egalitarians will leave people to perish simply because they made a minor mistake, and, second, that luck egalitarians rely on a conception of responsibility that fails to take account of people's evolving preferences.

\section{(a) Luck egalitarians' evaluation of mistakes}

One line of argument Fleurbaey pursues in relation to his Bert example is that luck egalitarianism implies that "[i]f you freely and deliberately make the slightest mistake that can put you in a very hazardous situation, a society complying with equal opportunity will quietly let you die" (Fleurbaey, 1995, p. 40). On this account, luck egalitarianism appears overly demanding and harsh in that it will punish people for being anything less than perfect. It requires that agents invariably display caution and immaculate behaviour, or else they will be left to face the consequences of their less than infallible choices, no matter how disastrous those consequences may be.

The luck egalitarian's response to this must take into account that we use the term "mistake" to describe (at least) two different phenomena: first, people sometimes describe deliberate decisions to take certain risks as "mistakes" when these choices turn out bad. We say for example, that with hindsight it was a "mistake" to trust a person; we knew at the time that there were good reasons not to trust her, but decided to take the risk anyway. Now that we know the negative outcome of this decision, we know that it was "mistaken". Second, when we say that someone made a "mistake", we could be talking about that person's inadvertently taking a certain risk, for example when she forgets to put on her seat-belt while driving a car. In considering whether Fleurbaey is right to say that luck egalitarians will leave people to die where this is the result of their mistakes, we will have to consider the luck egalitarian's response to both kinds of "mistakes" just described.

Consider first cases where agents consciously decide to accept certain risks that turn out bad for them. Here, as in the examples described earlier, the luck egalitarian would want to be certain that any unequal brute luck playing into the decision has been properly taken into account. Only where the decision was one of pure option luck, will the luck egalitarian deny compensation to the agent.

What is the luck egalitarian's response to the second kind of "mistake", where agents take certain risks without being aware of their doing so? Clearly, this is not what Fleurbaey has in mind when he describes Bert's situation; Bert "freely and deliberately" (Fleurbaey, 1995: 40) chooses not to wear a helmet, no "accidental" risk-taking is involved. However, we can think of situations where Bert ends up taking a certain risk inadvertently. For example, Bert may have accidentally fastened the straps on his helmet incorrectly, or he may have taken a wrong turn that led him off a quiet side road (where, presumably, driving without a helmet poses a much smaller risk) onto the motorway. In such cases, what will matter to the luck egalitarian's response is whether or not Bert has taken all the steps that could reasonably be expected of him; we apply the standard of reasonableness.

Assume that Bert fastened the strap of his helmet incorrectly so that it would provide no protection in case of an accident. What would matter from a luck egalitarian perspective is whether he has done what could reasonably be expected of him. For instance, has he read the helmet man- 
ual carefully, and did he double-check that the helmet fit securely before he drove off? To what extent Bert's accident will be regarded as a matter of brute luck rather than option luck will depend on an assessment of his precautionary actions with respect to this standard. If it turns out that Bert did everything we could reasonably expect of him, compensation will be forthcoming. Only if we think that Bert failed to live up to the standard of what we could reasonably expect of him would the luck egalitarian deny compensation.

Furthermore, as I mentioned above, the standard of reasonableness, when applied to particular cases, would have to be appropriately individuated so as to take account of any factors of unequal brute luck. If someone is unable to meet reasonable standards (or it is more difficult for her to do so) for reasons of unequal brute luck, the luck egalitarian would want to take this into account when deciding whether or not to provide compensation. So, for example, if we knew that Bert suffered from a certain kind of memory loss that caused him to forget to put on his helmet each time he used his motorbike, we are likely to describe this as a matter of unequal brute luck and refrain from holding him responsible. "Not holding him responsible" may, of course, take a number of different forms, of which compensation after an accident is only one. We might say, for example, that he should not be allowed to ride a motorbike, but compensate him for this restriction of his freedom. Or we might provide him with an insurance policy that will cover him for the risk he takes when riding his motorbike without a helmet. In each of these scenarios, we recognise that Bert's increased risk of accident is a result of unequal brute luck, so that the costs should be borne not by him but by society. Where an agent accidentally takes certain risks, then, the luck egalitarian will again take account of the various ways in which unequal brute luck may have contributed to her choice and regard inequalities arising from this decision as requiring at least partial compensation.

In response both to people consciously and inadvertently taking certain risks, then, the luck egalitarian will take account of how brute luck has played into the agent's failing to avoid the risk. Where unequal brute luck has contributed to this failure, luck egalitarians will want to provide at least partial compensation. It is, therefore, wrong to say that luck egalitarians will invariably leave people to die when their predicament is a result of such "mistakes". While a luck egalitarian will hold people to an individuated standard of reasonableness, this is not a standard of infallibility. We can therefore safely put aside the charge that luck egalitarianism is overdemanding in this respect.

\section{(b) Discontinuity of preferences}

Fleurbaey suggests a second argument to support the idea that luck egalitarians are unreasonably harsh on people who, through their own choices, face catastrophic outcomes. Fleurbaey suggests that the luck egalitarian's conception of responsibility is flawed in that it does not take into account the discontinuity of preferences caused by the "constant evolution of a person", which "dilutes the moral responsibility" (Fleurbaey, 1995, p. 42) an agent has for her actions. So, for example, an enlightened "Bert II" (Fleurbaey, 1995, p. 41) may after his accident recognise the recklessness of his behaviour, and would not again make the same decision that led to his accident. To accommodate this idea, the luck egalitarian principle would have to be reformulated so that

at every moment $m$, you should face the welfare prospects... that you would face if you had in the past made the decisions that at $m$ you would be inclined to make if you were to live again all your life up to $m$. (Fleurbaey, 1995, p. 42) 
Although Fleurbaey presents this position as a challenge to the luck egalitarian approach, luck egalitarians do not have to be entirely unsympathetic to the idea of evolving preferences. In many situations, agents can gain a proper understanding of the implications of their choices only after these choices have been made. The luck egalitarian can take this into account via the standard of reasonable expectations by asking what it would have been reasonable to expect the agent to know about the consequences of particular options available to her.

However, this will not go as far as giving people "at every moment $m$... the welfare prospects that you would face if you had in the past made the decisions that at $m$ you would be inclined to make" (Fleurbaey, 1995, p. 42). This suggestion seems unfair because even if someone regrets a choice she made, there may have been welfare benefits or costs associated with her earlier choices, which are not affected by the fact that she no longer identifies with those choices. For example, on Fleurbaey's proposal we would have to compensate Bert so that he reaches the welfare prospects he would have had, had he never wanted to ride his motorcycle uninsured and without a helmet, despite the fact that while he was doing so, he experienced a sense of enjoyment and greater well-being. Equally, it would seem unfair to take away resources from someone who has been saving throughout her life but later realises that she really should have spent her money on travelling while she was young. ${ }^{9}$

This response to Fleurbaey's argument supports the point that within the luck egalitarian approach, an agent's making a certain choice is not sufficient reason to hold her responsible for the outcome of that choice. Again, as in response to the over-demandingness argument, luck egalitarians will rely on a standard of reasonable expectations to respond to people's changing preferences: what could we have expected the agent to anticipate, given those of his circumstances and capacities that were affected by unequal brute luck? Should Bert have known just how bad the potential outcome of the risk he was taking was? As above, the answer to these questions will determine the extent to which we want to hold Bert responsible. However, in taking these considerations into account, luck egalitarians will not go as far as is required by Fleurbaey's principle: adjusting people's resource shares to what they would have had now, had all their previous choices been based on their current preferences, seems unfair in that it fails to take into account the welfare implications of earlier choices which are not affected by the fact that agents no longer identify with those choices.

\subsection{Opportunity costs}

One line of argument the luck egalitarian could pursue to respond to the Harshness Objection is to point out that any assistance we provide for the option luck victim is associated with opportunity costs and that this involves unfairness, ${ }^{10}$ if, for example, a reckless driver causes an

9 More recently, Fleurbaey has defended the principle that "people should enjoy situations that would have arisen from equal opportunities had they always acted according to their current mindset" (Fleurbaey, 2005, p. 30, emphasis in original). The luck egalitarian need not deny that, as Fleurbaey suggests, such a principle would enhance individual freedom, but it is not clear why considerations of freedom would affect what equality requires.

10 Consider, for example, Arneson's example of the rescue team that has to decide whether to rescue a group of reckless hikers, a group of experienced climbers who voluntarily chose a risky path, or a group of schoolchildren caught in an unexpected blizzard. In these circumstances, where the cost of rescuing one group is that neither of the other groups could be saved, it would seem wrong not to take questions of responsibility into account when deciding whom to rescue (Arneson, 2000a, p. 348). 
accident that not just injures herself but leaves another person with similar injuries, and only one of them could be provided with assistance, the luck egalitarian will have a good intuitive case for saying that it would be wrong to ignore questions of responsibility. ${ }^{11}$ Where helping the option luck victim leaves us with fewer resources to compensate victims of unequal brute luck, the luck egalitarian's "harshness" (if we still want to call it that) to the option luck victim does not seem unreasonable.

This response, however, makes things too easy for the luck egalitarian: it allows her to refer to the opportunity costs associated with aiding the option luck victim in defending her decision not to provide assistance. From the definitions luck egalitarians provide of their theories, however, it is not clear that it is this unfairness that motivates the decision to deny assistance to the option luck victim. Consider, for example, Cohen's suggestion that

[p]eople's advantages are unjustly unequal (or unjustly equal) when the inequality (or equality) reflects unequal access to advantage, as opposed to patterns of choice against a background of equality of access. (Cohen, 1989, p. 920)

Similarly, Arneson proposes the principle "it is bad if some people are worse off than others through no voluntary choice or fault of their own" (Arneson, 1989, p. 85). No reference is made to the unfairness of making people pay for the choices of others. A consistent application of luck egalitarianism, then, may require that we deny assistance to the option luck victim, even if there are no opportunity costs associated with doing so.

To see the implications of this point more clearly, assume a society of three people and an equal distribution of 10-10-10 (of whatever our chosen metric is; I will assume that it is some version of welfare). One of the members of this society decides to take a certain risk (we assume that this choice is a matter of pure option luck) and we end up with a distribution of 10-10-1. In the first scenario, we can help the option luck victim but only at a cost to the other two members of the society; we would end up with a distribution of 9-9-4. In the second scenario, however, we can provide this assistance without any opportunity cost to the other two. We could bale out the victim of bad option luck and leave the shares of the other two at 10, resulting in a distribution of 10-10-4. For the zero opportunity cost condition to be met, it must be true that the resources provided to the option luck victim would make no difference to the welfare of the other two people in our society (if these resources could make a difference to their well-being, they would have to be distributed equally to ensure the equality of the distribution); for example, the option luck victim might require a specific kind of medication which would be of no use to anyone else and which would be wasted if it was not provided to the option luck victim.

Now, it is apparent that in the first scenario, the luck egalitarian could point to the cost imposed on the other two members of that society to justify her decision to refuse assistance to the option luck victim: it would be unfair to make some people bear the costs of others' choices. Even in the second scenario, however, luck egalitarianism requires that we do not help the option luck victim: because, by definition, the pre-assistance distribution is equal, any deviation from it, even if the absolute positions of the other two members of our hypothetical society are

11 Such distinctions may, of course, be difficult to make on the spot and hence not recommend themselves for actual policy questions (see Anderson, 1999a, pp. 295-296, for this point); however, this does not diminish the case for wanting to accord priority to the innocent victim over the reckless driver. 
unchanged, is less equal. ${ }^{12}$ If we want to provide the strongest version of the Harshness Objection, then, we must add to it the assumption that any aid given to the option luck victim has no opportunity costs. However, as should be clear from the rather unlikely features of this example, not many real life situations will pass the "zero opportunity cost" test; the luck egalitarian's case for taking responsibility into account when making distributive decisions is strengthened by the fact that in most day-to-day situations, baling out the option luck victim will reduce the amount of resources available for the pursuit of other goals, such as the aim to compensate the victims of unequal brute luck.

\subsection{The "qualified" Harshness Objection}

In sections 3.1 to 3.3 I point to various ways in which the luck egalitarian can respond to the Harshness Objection. This response shows that the Harshness Objection is significantly weaker than we might think at first glance. However, although what I have said so far may weaken the Harshness Objection, it certainly does not rebut it. In this section, I want to rephrase the Harshness Objection in a way that takes account of the luck egalitarian's response. Having stated the Objection in what I think is its strongest form, I go on to consider its theoretical force against the luck egalitarian approach to social justice.

Let me briefly restate what I argued in the previous sections. Advocates of the Harshness Objection argue that luck egalitarians cannot take the severity of a situation into account when deciding whether or not to provide assistance, and they will have to deny assistance to agents who, as a result of their choices, face desolate circumstances. However, for the Harshness Objection to apply, the outcome in question must be the result of pure option luck; the effects unequal brute luck may have had on the range of options available to the agent, for example by excluding certain options from the agent's option set, must be taken into account by the luck egalitarian. For the same reason, we cannot accuse luck egalitarianism of being overly demanding of individuals: luck egalitarians will hold people responsible to an appropriately individuated standard of reasonableness. This standard allows us to compensate people for any negative consequences of the common mistakes we all make in everyday life and which it is not reasonable to expect people to avoid. The standard is individuated to take account of factors of brute luck that may have played into a person's failing to avoid a certain risk. Finally, I suggested that the Harshness Objection is strongest when built on the assumption that there is no opportunity cost to providing assistance to the option luck victim.

Given these considerations, the strongest formulation of the Harshness Objection is as follows:

When an agent, as a matter of pure option luck - i.e. when unequal brute luck did not affect the choice the agent faced (for example by limiting the range of options available or by increasing the cost of particular options), and when the agent failed to act in accordance with a

12 The problem described here is closely related to the familiar levelling-down objection in that the luck egalitarian (qua egalitarian) would have to reject the move from a distribution of 10-10-1 to 10-10-4 despite the fact that there is no one for whom the second distribution is worse and someone for whom it is better. The luck egalitarian can, of course, respond that there is a sense in which the first distribution is better - it is better from the point of view of equality - but that the second distribution may still be preferable overall (see Temkin, 1993). This pluralist stance, as discussed in section 1 above, is of course open to the luck egalitarian but she would have to admit that an "all things considered" endorsement of the second distribution involves a violation of her principle of equality. 
standard of reasonableness that was appropriately individuated to take account of the effects of unequal brute luck - ends up in desolate circumstances, then luck egalitarianism requires that we do not provide assistance to this agent, even if there are no opportunity costs associated with the provision of such assistance.

As should be clear from this formulation of the Harshness Objection as well as the points raised in the previous section, the range of cases to which the objection can be applied with full force is much smaller than we might think at first glance, and it is not clear whether there would be any such cases in the real world at all. For the luck egalitarian, intervention in the kind of cases described by advocates of the Objection will be required, as a matter of distributive justice, as long as unequal brute luck has affected the situation of the agent in question. The choice the agent faced (in terms of options open to her, costs associated with individual options, etc.) will almost always be influenced by unequal brute luck, making (some) assistance mandatory.

Now, how strong a challenge the Harshness Objection, appropriately refined, is for the luck egalitarian approach to social justice, depends to a significant extent on how we want to draw the distinction between brute luck and option luck; because unequal brute luck strikes me as an extremely pervasive feature of our lives, I am confident that in practice, not many situations will pass the "pure option luck" test. ${ }^{13}$ Nonetheless, two concerns raised by the Harshness Objection remain. First, even if it is true that the luck egalitarian will always want to provide some compensation, there may be situations where such partial compensation is insufficient to avoid the disastrous outcomes proponents of the Harshness Objection are concerned about. Second, even if the practical implications of the Harshness Objection are less severe than its advocates suggest, this does not necessarily diminish the theoretical importance of the Objection. We can think of stylised examples in which a person's desolate situation is purely a matter of option luck. We can assume, for example, that Bert's need for surgery satisfies all the conditions of pure option luck: the range of options available to him has not been affected by unequal brute luck and his action meets an appropriately individuated standard of reasonableness. Under those circumstances, even if all that is required to save Bert is a costless snap of the finger, the luck egalitarian cannot provide this without violating the requirements of her theory of equality. In the following section, I consider three possible strategies the luck egalitarian could pursue in responding to the Harshness Objection.

\section{$4 \quad$ Responding to the Harshness Objection: Three strategies}

How can luck egalitarianism respond to the problems raised by the Harshness Objection? I will consider three strategies the luck egalitarian might pursue. First, she can, as Arneson has recently suggested, combine luck egalitarianism with prioritarian considerations. Second, she could introduce a "minimum threshold" to which individuals would always be restored, irrespective of responsibility considerations. Finally, a society run on luck egalitarian terms could

13 It might be objected that if brute luck is as pervasive as I claim, luck egalitarianism is of little relevance to the real world. However, this objection holds only if we think that luck egalitarianism must be a theory of ex post compensation. Instead, we can think of luck egalitarianism as requiring that we aim to equalise background conditions so that the scope for unjustified inequalities decreases. However, because brute luck is so pervasive, I do not believe that such policies could ever make pure option luck possible. The argument of this paper - that partial compensation would always be forthcoming in response to the influence of unequal brute luck on individual choice - would therefore remain intact even after such policies were introduced (although partial compensation might be less). 
introduce a compulsory insurance scheme so that all citizens would be covered against risks that affect their ability to satisfy their most basic needs.

\subsection{Arneson's "responsibility-catering prioritarianism"}

Arneson responds to Anderson's critique by presenting what he calls "one (outlier) member of the luck egalitarian family" (Arneson, 2000a, p. 340): responsibility-catering prioritarianism (RCP). ${ }^{14}$ According to this approach, what is required by distributive justice is that we maximise a weighted function that combines luck egalitarian with prioritarian considerations.

The prioritarian's claim that "[b]enefiting people matters more the worse off these people are" (Parfit, 1997, p. 213) coheres well with the idea of a duty to relieve suffering mentioned in section 2.4. Arneson takes the prioritarian idea to imply that "one ought as a matter of justice to aid the unfortunate, and the more badly off someone is, the more urgent is the moral imperative to aid" (Arneson, 2000a, pp. 343, emphasis added). However, in line with the purely luck egalitarian approach of his earlier work, Arneson also suggests that the moral value of providing a gain in well-being is greater if the agent in question is less rather than more responsible for her present condition; in deciding how to distribute resources we must therefore take into account both prioritarian and luck egalitarian considerations.

Arneson does not intend to provide a fully formulated theory, and he does not say how the two considerations are to be weighed relative to one another. How this is to be done, is one obvious problem with Arneson's RCP: given that prioritarianism and luck egalitarianism are based on two very different understandings of what makes a distribution just, it is not clear how we would find a non-arbitrary way of determining the relative importance of each principle. More importantly, if RCP does have intuitive appeal, this will be a serious blow to the luck egalitarian project. If the luck egalitarian approach could maintain its appeal only when combined with a very different, arguably not even egalitarian, ${ }^{15}$ principle such as prioritarianism, this would mean that luck egalitarianism on its own can, at most, supply an incomplete theory of equality. This, of course, is far less than luck egalitarians have set out to provide.

\subsection{The "minimum threshold" strategy}

A different response to the problems posed by the Harshness Objection is to introduce a minimum threshold to which individuals would always be restored, even if it is pure option luck that causes them to fall below it. There are, of course, different ways of determining such a threshold and different arguments for it. For example, we could argue that an appropriate conception of equality must guarantee citizens a range of "functionings" that are indispensable to their agency. Such an argument is suggested by Anderson. She argues that there are "three aspects of individual functioning: as a human being, as a participant in a system of cooperative production, and as a citizen of a democratic state" (Anderson, 1999a, p. 317). Associated with each of these aspects are certain minimum resources. The ability to function as a human being, for example,

requires effective access to the means of sustaining one's biological existence - food, shelter,

14 Arneson (1999a, 1999b, 2000a, 2000b).

15 While some theorists have described prioritarianism as an egalitarian principle (e.g. McKerlie, 1994), there are important differences between the two approaches and it is reasonable to suggest that prioritarianism is not a version of egalitarianism at all; see Temkin (1993) for this point. 
clothing, medical care - and access to the basic conditions of human agency - knowledge of one's circumstances and options, the ability to deliberate about means and ends, the psychological conditions of autonomy, including the self-confidence to think and judge for oneself, freedom of thought and movement. (Anderson, 1999a, pp. 317-8)

On such an approach, people would be restored to the given minimum level of functionings if they fall below it, even if this is the result of option luck.

A different approach to determining a non-arbitrary threshold below which considerations of responsibility should not apply can be developed from Roger Crisp's arguments about the proper application of prioritarian considerations. He suggests that the hypothetical judgements of an impartial observer could help us provide "an account of distribution which allows us to give priority to those who are worse off when, and only when, these worse off are themselves badly off" (Crisp, 2003, p. 757, emphasis added). The "threshold at which compassion enters" (Crisp, 2003, p. 758) as determined by the impartial spectator could equally be argued to be the level below which responsibility considerations should not be applied, and to which people should be restored when they have, for whatever reason, fallen below it.

Approaches that aim to determine a level below which the luck egalitarian's consideration for responsibility should not be applied, might fare better than Arneson's because we can provide arguments for a minimum threshold that cohere with ideas underlying the luck egalitarian approach. For example, we could say that because luck egalitarianism is a theory that emphasises individual agency, we should not allow people to fall below a certain threshold below which such agency is impossible (even if the necessary intervention violates the agent's earlier choices). Nonetheless, it is clear that such approaches require that we violate basic luck egalitarian principles below whatever threshold is determined, which cannot be done without abandoning the singular, unified principle of luck egalitarianism; therefore, minimum threshold approaches can, like Arneson's RCP, only provide an unsatisfactory compromise on the luck egalitarian position. $^{16}$

\subsection{Compulsory insurance}

A third strategy the luck egalitarian could pursue to respond to the Harshness Objection is that of compulsory insurance. ${ }^{17}$ By requiring people to insure against certain risks, we can prevent situations such as those described in the Bert example from arising in the first place: if everyone is insured against particular risks, the luck egalitarian must provide appropriate compensation when agents suffer bad luck.

Probably the most attractive feature of compulsory insurance schemes as a response to the Harshness Objection is that (unlike the other approaches considered in this section) they allow us to avoid scenarios such as those described in Fleurbaey's Bert example without direct violation of

16 Dworkin (2002) suggests that the hypothetical insurance market he endorses as part of his theory of equality of resources would also result in the provision of a minimum standard of living to be ensured for everyone, regardless of certain of their choices. However, on the approach adopted in this paper, the hypothetical insurance market has to be regarded as a deviation from the basic luck egalitarian approach and not, as Dworkin suggests, as part of a theory of equality. On this point, see Otsuka (2002, 2004a, 2004b), Williams (2004), as well as Dworkin's reply to Otsuka (Dworkin 2004).

17 Dworkin, for example, suggests that citizens should be required to insure to the level determined by the hypothetical insurance device (Dworkin, 2002). 
luck egalitarian principles. If Bert had purchased appropriate insurance before riding his motorbike without wearing a helmet, the provision of assistance and/or compensation would not have been problematic for the luck egalitarian. However, compulsory insurance may be unattractive for other reasons: it could be paternalistic, and it involves restrictions on individual liberty.

Anderson discusses and rejects the compulsory insurance scheme as a possible response to the Harshness Objection (Anderson, 1999a, pp. 300-302). She suggests that a compulsory insurance scheme could only be motivated by the aim to protect agents from the harmful consequences of their own choices; such paternalist considerations are, of course, problematic within a liberal approach to social justice. However, it is not clear that the motivations underlying a compulsory insurance scheme would indeed have to be paternalistic. Paul Bou-Habib (2006), for example, suggests that because we are under a moral duty ${ }^{18}$ to aid those in need (including the option luck victim), we have a right to protect ourselves from having to bear the costs of others' deliberate and avoidable imprudence, including the right to require them to insure.

However, even if compulsory insurance is not paternalistic, it affects the range of choices open to people in a way that may impose limitations on their freedom. A mandatory insurance scheme forces people to spend resources to purchase protection they might not want, rather than letting them decide which risks they are willing to take. There may be instances where the compulsory insurance attached to a risky activity makes that activity unaffordable for someone. In such cases, it would not seem unreasonable for an agent to want to forego insurance, but this option would be removed by the compulsory insurance scheme. Its effects on individual freedom may, of course, not make a decisive case against compulsory insurance as a solution to the harshness objection; we may well think that certain infringements on individual liberty are acceptable if we can thereby avoid the Harshness Objection. However, this still leaves the luck egalitarian in the problematic position of recommending a theory of equality that can avoid harsh outcomes only at the expense of limiting individuals' freedom to take risks.

\section{Concluding remarks}

This paper assessed the extent to which the Harshness Objection raises problems for luck egalitarians. I argued that the Harshness Objection is less of a challenge for luck egalitarians than its advocates claim. Because the luck egalitarian will want to account for the influence of unequal brute luck on the choices people make, the range of inequalities the luck egalitarian will want to (at least partially) compensate for is wider than is implicitly assumed by proponents of the Harshness Objection; in fact, it is not clear that there would be any real world cases to which the objection could apply. Rather than treating all inequalities created by individuals' choices as a matter of option luck, the luck egalitarian will evaluate carefully how unequal brute luck may have affected the decision in question and provide compensation accordingly. However, these considerations do not amount to a full rebuttal of the Harshness Objection, and important problems remain. On the practical level, it is not clear that partial compensation will always be sufficient to avoid catastrophic outcomes. Furthermore, even if these practical concerns can be addressed, we can provide stylised examples where luck egalitarians will have to deny

18 Because, as I explain in section 1 above, luck egalitarians can be pluralists, they can affirm the existence of such a duty and hence accept Bou-Habib's argument without contradicting themselves. They might not be able to regard this as a duty of justice but they might, for example, see it as a duty of charity (see also Bou-Habib (2006) on this). 
compensation, even where such compensation could be provided without costs to ourselves or others. All of the three strategies considered in this paper as possible responses to these problems were problematic in that they either required a violation of luck egalitarian principles or a limitation of people's freedom to take risks.

\section{Acknowledgements}

I would like to thank Adam Swift for detailed comments and helpful discussions of earlier versions of this paper. I am also grateful to Nicholas Cheeseman, G. A. Cohen, the participants of the Nuffield College Political Theory Workshop, Oxford, as well as two referees of this journal for their suggestions. 


\section{References}

Anderson, E. (1999a). 'What is the point of equality?'. Ethics 109(2), 287-337.

Anderson, E. (1999b). Reply in BEARS symposium on Elizabeth Anderson's 'What is the point of equality?', http://www.brown.edu/Departments/Philosophy/bears/9912ande.html.

Arneson, R. J. (1989). 'Equality and equal opportunity for welfare'. Philosophical Studies 56(1), 77-93.

Arneson, R. J. (1990). 'Liberalism, distributive subjectivism, and equal opportunity for welfare'. Philosophy and Public Affairs 19(2), 158-194.

Arneson, R. J. (1999a). 'Equality of opportunity defended and recanted', The Journal of Political Philosophy 7(4), 488-497.

Arneson, R. J. (1999b). Comment, in BEARS symposium on Elizabeth Anderson's 'What is the point of equality?', http://www.brown.edu/Departments/Philosophy/bears/9904arne.html.

Arneson, R. J. (2000a). 'Luck egalitarianism and prioritarianism'. Ethics 110(2), 339-349.

Arneson, R. J. (2000b). 'Welfare should be the currency of justice'. Canadian Journal of Philosophy 30(4), 497-524.

Barry, N. (2006). 'Defending luck egalitarianism'. Journal of Applied Philosophy 23(1), 89-107.

Bou-Habib, P. (2006). 'Compulsory insurance without paternalism'. Utilitas 18(3), 243-263.

Cohen, G. A. (1989). 'On the currency of egalitarian justice'. Ethics 99(4), 906-944.

Cohen, G. A. (2004). 'Expensive taste rides again'. (In J. Burley (ed.), Dworkin and His Critics (pp. 3-29). Oxford: Blackwell.)

Crisp, R. (2003). 'Equality, priority and compassion'. Ethics 113(4), 745-763.

Dworkin, R. (1981). 'What is equality? Part 2: equality of resources'. Philosophy and Public Affairs 10(4), 283-345. (Reprinted in his Sovereign Virtue: The Theory and Practice of Equality (pp. 65-119). Cambridge, Mass.: Harvard University Press, 2000.)

Dworkin, R. (2000). Sovereign Virtue: The Theory and Practice of Equality. (Cambridge, Mass.: Harvard University Press).

Dworkin, R. (2002). 'Sovereign Virtue revisited'. Ethics 113(1), 106-143.

Dworkin, R. (2003). 'Equality, luck and hierarchy'. Philosophy and Public Affairs 31(2), 190198.

Dworkin, R. (2004). 'Ronald Dworkin replies'. (In J. Burley (ed.), Dworkin and His Critics (pp. 339-395). Oxford: Blackwell.)

Fleurbaey, M. (1995). 'Equal opportunity or equal social outcome'. Economics and Philosophy $11(1), 25-55$.

Fleurbaey, M. (2005). 'Freedom with forgiveness'. Politics, Philosophy \& Economics 4(1), 2967.

Goodin, R. (1985). 'Negating positive desert claims'. Political Theory 13(4), 575-598.

Kaufman, A. (2004). 'Choice, responsibility and equality'. Political Studies 52(4), 819-836.

Knight, C. (2005). 'In defence of luck egalitarianism'. Res Publica 11(1), 55-73.

Kymlicka, W. (2006). 'Left-liberalism revisited'. (In C. Sypnowich (ed.), The Egalitarian Conscience: Essays in Honour of G. A. Cohen (pp. 9-35). Oxford: Oxford University Press.)

Mayerfield, J. (1999). Suffering and Moral Responsibility. (Oxford: Oxford University Press).

McKerlie, D. (1994). 'Equality and priority'. Utilitas 6(1), 25-42.

Miller, D. (1997). 'Equality and justice'. Ratio 10(3), 222-237.

Otsuka, M. (2002). 'Luck, insurance and equality'. Ethics 113(1), 40-54. 
Otsuka, M. (2004a). 'Equality, ambition and insurance'. Supplement to the Proceedings of the Aristotelian Society 78(1), 151-166.

Otsuka, M. (2004b). 'Liberty, equality, envy, and abstraction'. (In J. Burley (ed.), Dworkin and His Critics (pp. 70-78). Oxford: Blackwell.)

Parfit, D. (1997). 'Equality and priority'. Ratio 10(3), 202-221.

Rakowski, E. (1991). Equal Justice. (Oxford: Clarendon Press).

Robinson, P. H. and Darley, J. M. (1995). Justice, Liability and Blame. (Boulder: Westview Press).

Stemplowska, Z. (2002). The Concept of Luck in Theories of Egalitarian Justice. M.Phil. Thesis. Oxford University.

Temkin, L. (1993). Inequality. (New York: Oxford University Press).

Temkin, L. (2003). 'Equality, priority or what?'. Economics and Philosophy 19(1), 61-87.

Vallentyne, P. (2002). 'Brute luck, option luck and equality of initial opportunities'. Ethics $112(3), 529-557$.

Williams, A. (2004). 'Equality, ambition and insurance', Supplement to the Proceedings of the Aristotelian Society 78(1), 131-150. 